Ensino, Saúde e Ambiente - V 7 (1), Edição Especial, maio de 2014

\title{
OFICINA TEMÁTICA SOBRE ARMAS QUÍMICAS NÃO LETAIS: A CAPSAICINA.
}

\section{THEMATIC WORKSHOP ON NON-LETHAL CHEMICAL WEAPONS: The CAPSAICIN .}

\author{
Florence M Cordeiro de Farias ${ }^{1}$, Márcia Narcizo Borges ${ }^{2}$, Marcos André Ferreira de \\ Araújo Santos ${ }^{3}$ e Susiane Martins Campos ${ }^{4}$. \\ ${ }^{1}$ Universidade Federal Fluminense-UFF, Pós-graduação em Ensino de Ciências da \\ Natureza/Departamento de Química Orgânica, e-mail- florencefarias@id.uff.br \\ ${ }^{2}$ Universidade Federal Fluminense-UFF, Pós-graduação em Ensino de Ciências da \\ Natureza/Departamento de Química Orgânica, e-mail- marcianb@id.uff.br \\ ${ }^{3}$ Universidade Federal Fluminense-UFF, Instituto de Química/ e-mail- marcosandre@id.uff.br \\ ${ }^{4}$ Universidade Federal Fluminense-UFF, Instituto de Química/ e-mail- susi_martins@yahoo.com.br
}

\begin{abstract}
RESUMO
Tomando como marco teórico a Aprendizagem Significativa Crítica, no presente trabalho descreve-se uma pesquisa intervencionista no ambiente escolar pelo uso de uma oficina temática sobre Armas Químicas Não-letais : A capsaicina como instrumento de aprendizagem. Esta oficina foi realizada no âmbito de uma escola pública estadual do Município de Niterói durante o mês de novembro de 2013 com alunos do terceiro ano do Ensino Médio. Os resultados obtidos evidenciam a importância de um ensino contextualizado que leve a uma aprendizagem que permita uma articulação entre os conteúdos apresentados e suas articulações com aplicações tecnológicas e as consequentes implicações políticas, econômicas e sociais.
\end{abstract}

Palavras-Chave: Ensino de Química, Aprendizagem Significativa, Oficina Temática, Armas Químicas Não Letais.

\begin{abstract}
Taking as theoretical march the Subversive Meaningful Learning, in this work we describe an interventional research within the school environment by the use of a thematic workshop on Chemical Weapons Non-lethal : The Capsaicin, as an instrument of learning. This workshop was held in a public school in the City of Niteroi during the month of November, 2013 with students of the 3th grade of middle school. The results obtained demonstrate the importance of an education that leads to a contextualized learning that permits a linkage between the presented content with technological applications and the consequent politics, social and environment implications.
\end{abstract}

Kew words: Chemistry Teaching, Meaningful Learning, Thematic Workshop, NonLethal Chemical Weapons.

Edição Especial com os melhores trabalhos apresentados no IV ENECiências: UFF - 13 a 16 de maio de 2014.

ISSN 1983-7011 


\section{INTRODUÇÃO}

Os problemas do Ensino de Química no Nível Médio são motivos de debate não é de hoje. Uma prática de ensino descontextualizado, reduzido a um tratamento disciplinar e "conteudista", passando ao aluno uma ideia de pouca importância dos conteúdos em sua formação, vem sendo relatada na literatura como uma das principais causas do desinteresse dos estudantes por essa disciplina (CHASSOT, 1995; MACHADO, 2013). Críticas a essa prática de ensino e novas propostas de formas para alterar esta realidade têm sido constantes na literatura. Nesse sentido, as políticas nacionais para o Ensino Médio apontam, no processo de ensino/aprendizagem, para a necessidade do desenvolvimento de competências cognitivas e culturais que permitam ao aluno um desenvolvimento humano necessário ao exercício da cidadania, ao desenvolvimento social e à inserção no processo produtivo. Com esse enfoque os Parâmetros Curriculares Nacionais, os PCN+ (BRASIL,2002) defendem uma formação escolar baseada no compartilhamento e articulação de linguagem e modelos que compõem cada cultura científica, pelo estabelecimento de mediações capazes de produzir o conhecimento escolar na inter-relação dinâmica de conceitos cotidianos e científicos diversificados. Esse processo de formação é favorecido quando os professores, em sua prática pedagógica, inserem os objetos de estudo em situações de vivências dos alunos, nos fenômenos naturais e artificiais e nas suas aplicações tecnológicas e consequências ambientais.

Para a consolidação dessa metodologia de ensino/ aprendizado, é fundamental, dentre outros fatores, investimentos na atuação e qualificação da formação dos professores (Cursos de Licenciaturas). Os futuros Professores de Química serão os autores diretos dessa prática pedagógica e para isso tem de estar preparados. De acordo com Carvalho (2003) “ensino, aprendizagem e formação de professores são três conceitos que têm ligações bastante profundas e aparecem estreitamente interrelacionados".

Com esse enfoque e buscando uma associação entre formação de professores e atuação no Ensino Médio, neste trabalho descrevemos a aplicação de uma oficina temática com o tema “Armas Químicas Não Letais: A Capsaicina” como instrumento 
metodológico para o ensino do tópico Funções Orgânicas e Relação EstruturaPropriedades. Essa oficina foi executada como um Projeto do Programa de Bolsa de Iniciação à Docência (PIBID) da Universidade Federal Fluminense (UFF) no Colégio Estadual Manuel de Abreu localizado no bairro de Icaraí, Niterói, Rio de Janeiro. A escolha desse tema se justificou em função das manifestações populares vividas no Brasil durante o ano de 2013 em que as Polícias Militares de vários estados, inclusive do Rio de Janeiro, fizeram uso intenso de gases lacrimogêneos e spray de pimenta e que foi motivo de muita discussão na mídia e população em geral. O senso comum divulgou o uso do vinagre como antídoto para esses gases e, por conta disso a mídia passou a denominar essas manifestações da "Revolta do Vinagre".

A escolha da oficina temática como instrumento metodológico é explicada na medida em que o tema abordado é apresentado de forma contextualizada, problematizada, procurando envolver os alunos em um processo ativo de construção de seu próprio conhecimento e de reflexões que permitam contribuir para a tomada de decisões (MARCONDES, 2008).

\section{REFERENCIAL TEÓRICO}

Considerando-se que a Química é uma das ciências responsáveis pelo grande desenvolvimento científico tecnológico do mundo atual e cujas consequências têm alcance social, político e econômico, não é admissível que o seu ensino se reduza à transmissão de informações, definições e leis isoladas, sem qualquer preocupação contextual. É necessário que esse ensino proporcione o letramento científico através de uma ação docente direcionada para a apropriação crítica do conhecimento científico pelo aluno, de modo que efetivamente se incorpore no universo das representações sociais e se incorpore como cultura (DELIZOIKOV e cols., 2012).

Para incorporar o conhecimento como cultura espera-se que o aluno aprenda os conceitos de forma significativa, conceito aqui definido (AUSUBEL, 1980) como sendo "objetos, eventos, situações ou propriedades que possuem atributos essenciais comuns que são designados por algum signo ou símbolo”.

Edição Especial com os melhores trabalhos apresentados no IV ENECiências: UFF - 13 a 16 de maio de 2014. 


\section{Ensino, Saúde e Ambiente - V 7 (1), Edição Especial, maio de 2014}

A aprendizagem acontece quando a pessoa estabelece relações entre os novos conceitos com as ideias presentes na sua estrutura cognitiva (MOREIRA,2011), ou seja, quando ocorre uma modificação das estruturas mentais do aprendiz de tal modo que ele consiga reelaborar novos significados para os conceitos. Em outras palavras, deve ocorrer uma interação entre os novos conhecimentos e aqueles especificamente relevantes já existentes na estrutura cognitiva do aprendiz, ou seja, seu conhecimento prévio. (MOREIRA, 2003) Para que os conhecimentos prévios se reestruturem é necessário que o aprendiz entre em contato com novas condições de estudos ou informações que o desafiem a reprocessar o pensamento. Assim, quando um educador quer estimular em seus alunos uma aprendizagem significativa, ele deve considerar quais conhecimentos prévios o aluno possui sobre determinado tema (AUSUBEL,1980). Para isso, muitas vezes, o professor tem de lançar mão dos chamados organizadores prévios que são os vários tipos de materiais que podem ser usados visando que o aprendiz resgate os conhecimentos prévios que possui sobre determinado assunto. Os organizadores prévios são materiais introduzidos antes do novo conteúdo de aprendizagem e são apresentados em um nível mais alto de abstração, generalidade e inclusividade do conteúdo a ser apresentado. Podem ser vídeos, jogos, textos, etc (KILL, HARTWIG e FERREIRA, 2011). Além disso, para que ocorra uma aprendizagem significativa o aluno deve querer aprender, deve ser estimular a vontade do aluno em aprender sobre o assunto. Nesse caso, a contextualização é importante na medida em que permite ao aluno a percepção da importância daquele conhecimento.

A partir desta teoria "ausebeliana” Moreira (2005 e 2011) propõe uma Teoria da Aprendizagem Significativa Crítica (subversiva, antropológica), o que significa dizer que na sociedade contemporânea não basta adquirir novos conhecimentos de maneira significativa, é preciso adquiri-los criticamente: “Ao mesmo tempo em que é preciso viver nessa sociedade, integrar-se a ela, é necessário também ser crítico dela, distanciarse dela e de seus conhecimentos quando ela está perdendo o rumo" (MOREIRA, 2011).

Para isso devem ser observados princípios (MOREIRA, 2011) dos quais podemos destacar, além do conhecimento prévio, a interação social e o questionamento (aprender e ensinar perguntas e não respostas), a aprendizagem pelo erro, a incerteza do conhecimento, o uso de materiais didáticos e estratégias diversos. É fundamental para o professor avaliar qual é a estratégia didática mais adequada a ser utilizada em dado 


\section{Ensino, Saúde e Ambiente - V 7 (1), Edição Especial, maio de 2014}

momento, tendo consciência que mesmo as estratégias mais modernas não se aplicam a todas as situações e nem a todos os tipos de alunos e não garantem um modelo de ensino não-tradicional. Portanto, mesmo que o professor tenha poucos recursos, deve se certificar de que está oferecendo condições para que seus alunos se coloquem numa condição ativa de aprendizagem (MOREIRA, 2011):

\footnotetext{
"A facilitação da aprendizagem significativa depende muito mais de uma nova postura docente, de uma nova diretriz escolar, do que de novas metodologias, mesmo as mais modernas tecnologias de informação e comunicação" (MOREIRA, 2011, p.51).
}

Tomando por base a Teoria da Aprendizagem Significativa Crítica, para que o conhecimento químico seja entendido e contribua para o desenvolvimento das competências dos alunos o uso da oficina temática é um instrumento de grande valia. Segundo Marcondes (2008) uma oficina temática deve buscar trabalhar os conhecimentos de forma inter-relacionada e contextualizada envolvendo os alunos em um processo ativo de construção de seu próprio conhecimento e de reflexões que possam contribuir para análises críticas e tomadas de decisões. Assim, em uma oficina temática, o cotidiano é problematizado e estudado com base em conhecimentos científicos e de outros relativos a aspectos socioeconômicos, históricos e éticos que possam auxiliar a compreensão da situação em foco (GIL-PÉREZ e cols, 2005).

\section{METODOLOGIA}

Este trabalho aborda uma pesquisa qualitativa de intervenção escolar onde buscou-se investigar o quanto a contextualização do ensino e a análise das implicações sociais do uso dos conhecimentos apresentados podem favorecer a construção de conhecimentos básicos em química. Com este enfoque, utilizou-se como instrumento metodológico uma oficina de ensino com o tema Armas Químicas Não Letais : A Capsaicina.

Essa oficina temática foi elaborada por dois licenciandos em Química do Programa PIBID/UFF e aplicada em duas aulas de 50 minutos cada para duas turmas do terceiro ano do Ensino Médio (54 alunos no total) do Colégio Estadual Manuel de Abreu localizada no bairro de Icaraí, município de Niterói. O bairro de Icaraí é uma área nobre Edição Especial com os melhores trabalhos apresentados no IV ENECiências: UFF - 13 a 16 de maio de 2014. 


\section{Ensino, Saúde e Ambiente - V 7 (1), Edição Especial, maio de 2014}

do município e os alunos da escola, de acordo com entrevista realizada com a diretora pelos licenciandos do PIBID, apresentam perfil social diverso: Há desde alunos de comunidades locais (Morro do Cavalão) até alunos de bairros nobres da cidade do Rio de Janeiro (Copacabana), em função de uma política de seleção e redistribuição de alunos realizada pela Secretaria de Educação do Estado do Rio de Janeiro. A faixa etária dos alunos dessas turmas de terceiro ano do Ensino Médio varia de 16 a 18 anos.

Na primeira etapa de nosso trabalho realizamos junto com os licenciandos uma discussão sobre as vantagens do uso da oficina temática como instrumento pedagógico, um levantamento na literatura sobre armas químicas lacrimogêneas e elaboramos a forma de concretização da oficina.

O desenvolvimento de uma oficina se dá em uma sequência que considera três momentos pedagógicos: a problematização, a organização e a aplicação do conhecimento (DELIZOIKOV e cols, 2009). Na primeira etapa é apresentado o(s) problema(s) e onde deve ser incentivada a participação dos alunos pela manifestação de suas ideias e conceitos sobre o assunto. Deve-se buscar, além da problematização, o compartilhamento do conhecimento que o grupo possui. O segundo momento pedagógico é caracterizado pela apresentação dos conhecimentos específicos sobre o assunto e no terceiro momento faz-se uma discussão sobre como o assunto abordado é aplicado no cotidiano.

Especificamente sobre o tema de nossa oficina, na etapa de problematização fizemos uso, como organizador prévio, de um texto elaborado pelos dois licenciandos. A partir daí levantou-se a discussão sobre as manifestações e o uso dos gases lacrimogêneos, conceitos de armas químicas letais/não letais (FRANÇA, SILVA e de CASTRO, 2010; FIGUEIROA-VILLAR e cols, 2012), suas utilizações em guerras, aspectos legais (MADDARENA e cols,2009) e no caso do gás de pimenta, a associação do seu efeito fisiológico com os das pimentas de uso culinário e o uso divulgado pelo senso comum do vinagre como antídoto. Nesse momento foi aplicada uma diagnose na forma de um questionário aberto que versou sobre os conceitos a serem trabalhados no segundo momento pedagógico e onde também solicitou-se uma avaliação do primeiro momento da oficina.

No segundo momento pedagógico trabalhou-se o reconhecimento das funções orgânicas presentes na molécula da capsaicina e da correlação com propriedades químicas em função desses grupos funcionais (polaridade, caráter ácido/base). 


\section{Ensino, Saúde e Ambiente - V 7 (1), Edição Especial, maio de 2014}

No terceiro momento pedagógico, o da aplicação do conhecimento, foi solicitado aos alunos que retomassem a discussão iniciada no primeiro momento, mas agora com informações adicionais baseadas no que foi visto na oficina.

A oficina foi finalizada com a avaliação, por parte dos alunos da escola e dos licenciados, sobre a metodologia pedagógica (oficina temática) utilizada. A avaliação por parte dos alunos da escola foi feita usando como instrumentos um questionário semiestruturado abordando os conteúdos apresentados e entrevistas de avaliação do instrumento pedagógico, enquanto os licenciandos elaboraram um relatório de avaliação.

\section{RESULTADOS}

No primeiro momento pedagógico da oficina introduziu-se o tema que seria trabalhado. Com essa finalidade os licenciandos apresentaram à turma, como organizador prévio, um texto elaborado por eles onde foram apresentados aspectos históricos do uso de armas químicas e biológicas letais e não letais, a apropriação de sua fabricação pelas indústrias e seu uso nas duas Guerras Mundiais (FRANÇA, SILVA e de CASTRO, 2010; FIGUEIROA-VILLAR e cols, 2012. MADDARENA e cols, 2009), a proibição do uso de armas químicas letais: Convenção sobre Armas Químicas apresentada à Convenção das Nações Unidas em 1993 (UNOG, 1993), · com o consequente uso indiscriminado de armas químicas não letais· . Além desses aspectos históricos, conceituais e legais, o texto também fez referências, com apresentação de fotografias, às manifestações populares de 1968 e de 2013, o uso de gás lacrimogêneo e do spray de pimenta para conter essas manifestações, a utilização divulgada pelo senso comum do vinagre como antídoto, chamando a atenção, em relação a esse último aspecto, da necessidade da aquisição de conhecimentos para a tomada de decisões:

"Como a maioria dos casos, essa informação tornou-se uma verdade, sem ao menos saber se realmente procede, se é nocivo à saúde. E é a partir deste problema que a Química com seus princípios e teorias esclarece se essa prática tem um fundo de é VERDADE ou se é MITO. Pois a Química não é uma disciplina que devemos aprender na escola e depois esquecer, como a maiorias das pessoas pensam. A Química está no nosso cotidiano e está em tudo, basta termos a percepção disso.” (SANTOS e MARTINS,2013).

Após a leitura do texto iniciou-se uma etapa de discussão sobre as manifestações e solicitou-se aos alunos que respondessem a um questionário aberto contendo três 
questões sobre: 1) O que seriam gases lacrimogêneos; 2) Se eles acreditavam que o vinagre neutralizava os efeitos do gás de pimenta e porque e 3) Uma avaliação sobre a "aula" dada. Ressalta-se que nessa etapa ainda não havia sido introduzido nenhum conceito químico que permitisse as respostas a esse questionário diagnose, isso é, as respostas obtidas vinham dos conhecimentos prévios dos alunos. Essa diagnose mostrou que todos tinham noção do que eram gases lacrimogêneos (“que fazem chorar"), embora nenhuma resposta constasse a presença de substâncias orgânicas (princípios ativos), cerca de $60 \%$ acreditavam que o vinagre seria um antídoto para o gás de pimenta e todos afirmaram gostar da aula que levantava discussões atuais e permitia que eles discutissem entre si.

No segundo momento pedagógico da oficina foi dada uma aula sobre a estrutura química da capsaicina ( constituinte do spray de pimenta, Figura 1), destacando as funções orgânicas presente na molécula e correlacionando a estrutura com as suas propriedades.

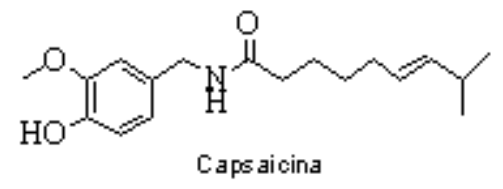

Figura 1 : Estrutura molecular da Capsaicina.

Normalmente nesse momento de uma oficina temática é realizado algum experimento sobre o tema. Como na escola onde foi aplicada a oficina não havia condições para a extração da capsaicina a mesma foi realizada (extração por Soxleht da de pimenta malagueta utilizando hexano como solvente) em um laboratório do Instituto de Química da UFF. A amostra obtida foi apresentada aos alunos para que percebessem suas propriedades organolépticas e a técnica da extração pelo uso de fotografias da experiência (Figura 2). 


\section{Ensino, Saúde e Ambiente - V 7 (1), Edição Especial, maio de 2014}

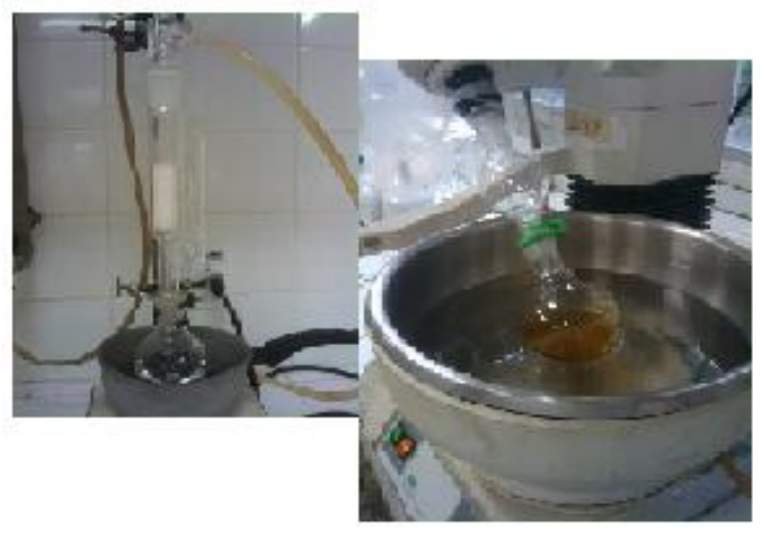

Figura 2: Extração da capsaicina.

No terceiro momento, fase de aplicação do conhecimento, iniciou-se um processo com questionamentos para se investigar se a estrutura possuía características básicas que justificassem o uso de vinagre (solução ácida) como antídoto por uma reação de neutralização. Concluiu-se sobre a inconsistência dessa afirmação e essa constatação desencadeou uma discussão sobre a necessidade de uma análise cuidadosa sobre as afirmações veiculadas pelo senso comum e pela mídia.

$\mathrm{Na}$ finalização da oficina solicitou-se aos alunos que respondessem a um questionário semiestruturado envolvendo os conceitos abordados: Que são gases lacrimogêneos, reconhecimento dos grupos funcionais da capsaicina, explicação de porque o vinagre não atua como antídoto e finalizando solicitava-se uma opinião sobre as "aulas" dadas. No que concerne ao conceito de gases lacrimogêneos $60 \%$ dos alunos associaram, na resposta, a propriedade lacrimejante à molécula existente em várias espécies de pimenta. 75\% dos alunos acertaram os grupos funcionais presentes (pergunta na forma de múltipla escolha) e destes, metade discutiu o fato de não haver grupos funcionais na molécula de capsaicina que pudessem reagir com o vinagre (solução aquosa de ácido acético) formando uma substância mais fácil de ser retirada com água.

As respostas em relação a avaliação da oficina mostraram que o uso desse instrumento foi válido:

“Gostei muito e na minha opinião foi mais fácil de entender. Acho que deveria ter mais." 
"Sim, gostei. Sim, foi mais fácil de compreender, acho que deveriam ter mais aulas assim. Só não gostei do teste.”

"A aula foi boa e desenvolveu o assunto de uma forma diferente e atual. Seria legal ter mais aulas assim.”

"Gostei, pois foi uma aula mais dinâmica. Com todos participando e expondo suas ideias e informações, torna mais fácil o aprendizado."

A avaliação dos licenciandos que elaboraram e aplicaram a oficina também foi positiva conforme mostrado nos relatos:

"A oficina foi uma experiência positiva para minha formação como docente. Através da oficina aprendi um método mais dinâmico de ensinar e percebi que para os alunos tornou-se mais interessante aprender deste jeito. Percebi também que houve uma grande interação entre professor e o aluno. Em minha opinião a oficina pode ser utilizada como um instrumento facilitador na aprendizagem de Química.”

"Confesso que estava com um pouco de receio e inseguro. Apesar de ser um tema polêmico, requer envolvimento da parte do aluno, e o problema estaria aí, na interação, no reconhecimento do problema, na formação das opiniões de forma coerente. No entanto, exatamente isso que deu o grande estímulo para mim, os alunos estavam realmente interessados e participando da aula, ou melhor, compondo a aula, compondo o debate que foi planejado... Ao final, fiquei surpreso, de uma forma geral, percebeu-se que estavam satisfeitos com a aula, mas não esperava que fossem aplaudir quando terminássemos e com certeza isso ficou marcado por mim...".

\section{CONCLUSÃO}

Edição Especial com os melhores trabalhos apresentados no IV ENECiências: UFF - 13 a 16 de maio de 2014. 
Os resultados encontrados na diagnose somados à participação ativa dos sujeitos (licenciandos e alunos da escola) desta pesquisa durante toda a oficina evidenciam que a utilização de temas contextualizados para o ensino de química aumentam a compreensão e o interesse dos alunos pela disciplina. O uso da oficina temática mostrou-se efetiva para o objetivo proposto, na medida em que criou um ambiente informal propício para interações dialógicas entre o professor e os alunos, o que permitiu uma discussão ampla e que, ao nosso entender, permitiu a construção e reconstrução de significados. Espera-se, que de acordo com o proposto por Marcondes (2008) as reflexões provocadas durante esta oficina temática tenham contribuído para o desenvolvimento de competências que os prepare para uma vida adulta como cidadãos críticos aptos a intervir na sociedade.

\section{AGRADECIMENTOS:}

Aos alunos e professores do Colégio Estadual Manuel de Abreu que participaram do projeto e à CAPES pelas bolsas PIBID.

\section{REFERÊNCIAS BIBLIOGRÁGICAS}

AUSUBEL, D. P.; NOVAK, J. D.; HANESIAN, H. Psicologia educacional. 2. ed. Rio de Janeiro: Interamericana, 1980.

BRASIL, Ministério da Educação (MEC), Secretaria de Educação Média e Tecnológica (Semtec). PCN + Ensino médio: orientações educacionais complementares aos Parâmetros Curriculares Nacionais - Ciências da Natureza, Matemática e suas Tecnologias. Brasília: MEC/Semtec, 2002.

CARVALHO, A. M. P. Formação docente em ciências: Memórias e Práticas. Niterói: EDUFF, p. 117, 2003.

CHASSOT, A. I. Para quem é útil o ensino? Alternativas para um ensino (de química) mais crítico. Canoas: Editora da ULBRA, 1995.

DELIZOIKOV,D; ANGOTTI, J. A.; PERnAMBUCO, M. M. Ensino de Ciências: Fundamentos e Métodos. São Paulo: Cortez., 2012. 
FRANÇA, T. C. C; SILVA, G. R.; de CASTRO, A. T. Defesa Química: Uma Nova Disciplina no Ensino de Química, Rev. Virtual de Química (http://www.uff.br/rvq),v.2 n.2, p.84-104, 2010.

FIGUEROA-VILLAR, J. D.; SILVA, G. R.; BORGES Jr; de CASTRO, A. T. , Defesa Química: Histórico, Classificação dos Agentes de Guerra e Ação dos Neurotóxicos. Química Nova,v. 35 ,n.10, p.2083-2091, 2012.

GIL-PÉREZ, D; MACEDO, B.; SIFREDO, C.; VALDÉS, P.; VILCHES, A ¿Cómo promove el interés por la cultura científica? Una propuesta didáctica fundamentada para La educación científica de jóvenes de 15 a 18 años. In: Década de La Educación para el Desarrollo Sostenible. UNESCO (Oficina Regional de Educación para América latina y el Caribe), 2005.

KIILL, K. B.; HARTWIG, D. R.; FERREIRA, L. H.,Características da Aprendizagem Significativa em Proposições Escritas: Um Estudo a partir de Material Instrucional Teórico e Experimental. III Encontro Nacional de Pesquisas em Educação em Ciências-III ENPEC, ATAS. Atibaia:ABRAPEC, 2001.

MACHADO, J. R. C. Considerações sobre o ensino de Química. Disponível em http://www.ufpa.br/eduquim/consideracoes.htm, acessado em 10 de janeiro de 2014.

MADDARENA, G. L.; dos SANTOS, C. P.; DIAS, W. O.; ROCHA, M. F. ; MORAES NETTO, L. N. Caderno Didático do Curso de Extensão em Armas Não Letais, Departamento da Polícia Federal, Brasília: Secretaria de Segurança Pública, 2009.

MARCONDES, M. E. R., Proposições Metodológicas Para O Ensino De Química:Oficinas Temáticas Para A Aprendizagem Da Ciência e O Desenvolvimento Da Cidadania. Em Extensão, v.7, p 67-77, 2008.

MOREIRA, M. A. Linguagem e Aprendizagem Significativa. Disponível em http://www.if.ufrgs.br/ moreira/linguagem.pdf, acessado em 30 de janeiro de 2014.

MOREIRA, M.A., Aprendizaje Significativo Crítico. Indivisa, Boletín de Estúdios e Investigación, n.6,2005.

MOREIRA, M. A Aprendizagem Significativa: a teoria e textos complementares. São Paulo: Editora da Física, 2011.

SANTOS, M. A. F. de A. e MARTINS, S. As Manifestações e os Gases Lacrimogêneos. Texto base apresentado no Colégio Manuel de Abreu, Niterói, Rio de Janeiro na Oficina temática Sobre Gases Lacrimogêneos, 2013.

UNOG, The United Nations Office at Geneva Biological Weapon Convention. The Biological Weapons Convention, 1993. Disponível em http://www.unog.ch., ,acessado em 10 de junho de 2013. 